\title{
Experimental assessment of head losses through elliptical and sharp-edged orifices
}

\author{
N.J. Adam, G. De Cesare \& A.J. Schleiss \\ Laboratory of Hydraulic Constructions ( $\mathrm{LCH}$ ) \\ École Polytechnique Fédérale de Lausanne, Lausanne, Switzerland
}

\begin{abstract}
Due to the European electricity market liberalization and the appearance of other renewable electricity producers, an increase of installed peak power capacity is relevant to provide larger amount of electricity in a shorter turbine duration. When the discharge increase is not too large, it is frequently efficient to place an orifice at the entrance of the existing surge tank. Actually, the surge tank modifications have to be designed case-by-case. The introduction of head losses helps to manage maximum and minimum water level following the management of downstream discharge control and transient events. It allows to keep the same safety level. The placed orifice should commonly produce asymmetric losses. It is important to note that target head losses are evaluated with a unidimensional numerical model which performs transient simulation for relevant flow directions in the whole water way system and hydropower plant. A previous study performed by the authors focused on the effects of sharp-edged orifice parameters. This research carries out the analysis of corresponding elliptical orifices to tested sharp-edged orifices. The goal is to evaluate the head loss modification in both directions due to the shape change.
\end{abstract}

\section{INTRODUCTION}

Surge tank orifices allow introducing head losses between a surge tank and the waterway. The introduction of an orifice allows reducing extreme water level in the tank and, by extension, to keep a same surge tank geometry while a refurbishment (increase of discharge). Refurbishments enable to increase installed capacity in the power houses in order to improve their ability to produce large amount of electricity in short laps of time.

During the study of a hydroelectric plant refurbishment, the first step is generally to simulate the whole waterway with a 1-dimensionnal transient model using either the method of characteristics (Boillat and de Souza 2004) or a similitude between hydraulic behavior and interaction with hydrualic machinery and electro-mechanical equipment (Nicolet 2007, Alligne et al. 2014). The results of this step are actually values of head loss coefficients in both direction, i.e. flowing in and out the surge tank. In some cases, these coefficient might be different by introducing a high asymmetry (Gabl et al. 2014) . Due to a lack of knowledge of the effect of orifice geometry on head losses, the geometry producing head losses are usually evaluated case-by-case with a physical model.

This study focuses a rounding of standard orifice shapes (International Standard 2003) and assesses the effect of this geometry change from angular to rounded forms on asymmetry and head losses in both directions. Rounded-edged orifices decrease the downstream pressure drop in compare to sharp-edged orifices for same total head losses (Zhang and Cai 1999).

The first part of the study performs experiments on physical set-up. Then, the second part performs simulations on numerical set-up to extend physical results.

\section{PHYSICAL SET-UP}

\subsection{Tested orifices}

The main research goal is to compare the influence of orifice shape on head losses. Hereafter, there are two shapes, i.e. sharp-edged (Figure 1) and elliptical (Figure 2). The sharp-edged geometry comes from the standard definition of an orifice flowmeter (International Standard 2003). Higher thickness are tested in this study.

Standard orifices are characterized with four dimensionless numbers: $\beta$ the contraction ratio, $\alpha$ the orifice thickness ration, $\alpha_{i}$ the inner thickness ratio and $\theta$ the sharp-edged angle. The orifice asymmetry is introduced by modifying $\alpha_{i}$ and $\theta$.

Each elliptical orifice is related to a sharp-edged one. The ellipse parameters, i.e. centre position $(\mathrm{x}, \mathrm{y})$ and ellipse axis $(a, b)$ in Figure 2, are defined by applying the least square method as shown in Figure 3 . The goal is to minimize the area between both sharp-edged and ellipse lines. Consequently, elliptical 


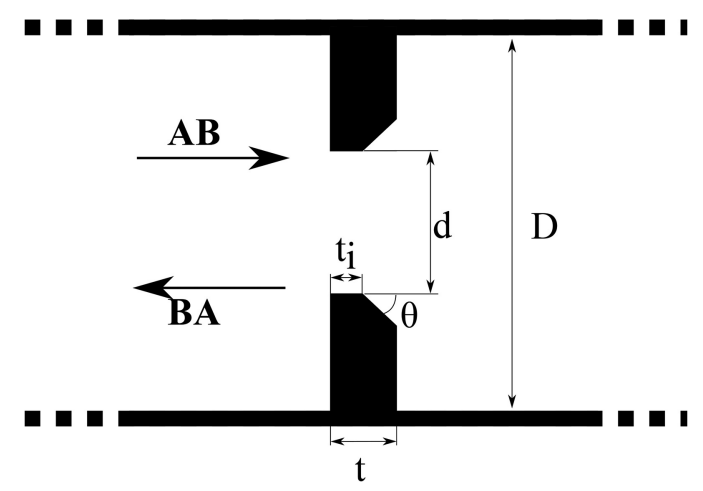

Figure 1. Standard (sharp-edged) orifice.

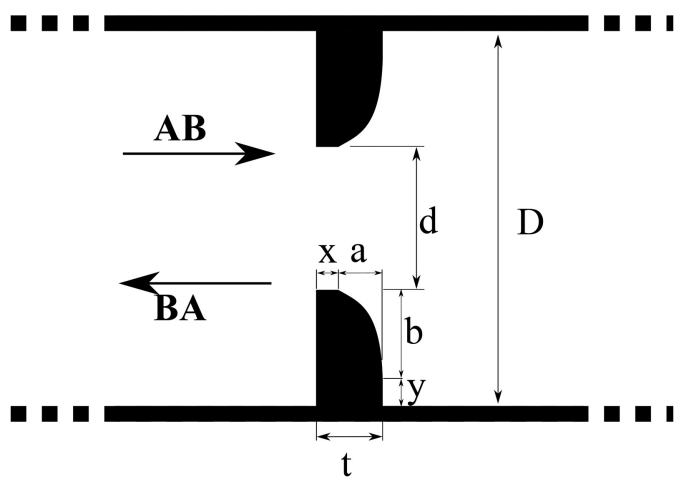

Figure 2. Elliptical orifice.

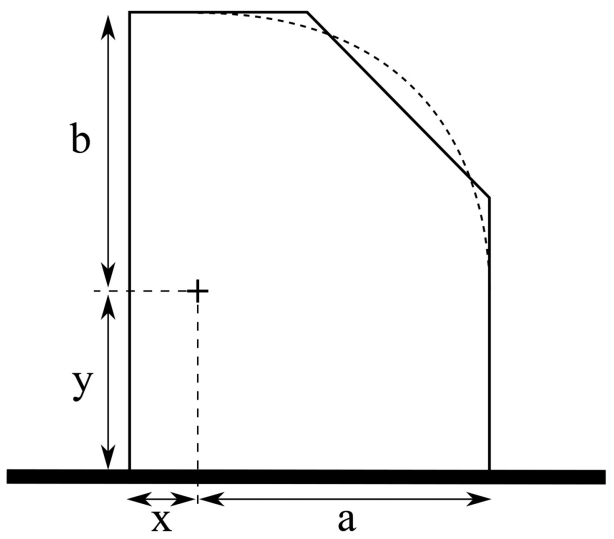

Figure 3. Elliptical approach corresponding to a sharp-edge shape.

orifices are characterized by six dimensionless numbers: The same $\beta$ and $\alpha$ as for standard orifices, $\left(\alpha_{x}, \beta_{y}\right)$ the ellipse dimensionless centre coordinates and $\left(\alpha_{a}, \beta_{b}\right)$ the ellipse dimensionless main axis. $\alpha_{x}$ can be directly compared to the standard orifice inner thickness ratio, $\alpha_{i}$.

Table 1 shows the different characteristics for both geometries. Note that this approach is not relevant for an angle of 0 .

\subsection{Set-up}

The experimental set-up at the Laboratory of Hydraulic Constructions (LCH) at EPFL Lausanne is shown in Figure 4. The main pipe, where orifices are tested, has an inner diameter $D 0.216 \mathrm{~m}$ and a length of $4 m$ while the water supply and restitution of the set-up have a standard diameter of $0.150 \mathrm{~m}$ of the laboratory supply.

Head losses are evaluated in both flow directions (From inlet A to exit B and from inlet B to exit A). For each direction, one flowmeter, $\mathrm{A}$ or $\mathrm{B}$, records the discharge flowing in the set-up with an electromagnetics flowmeter (Endress-Hauser PROMAG 50W).

Furthermore, there are 12 sections on each transparent PVC pipe where the pressure is recorded. The pressure is recorded by piezoresistive pressure sensors averaged on 4 points equally placed over the perimeter (Figure 4).

\section{METHOD}

For each orifice described in section 2.1, head losses are evaluated two times for a set of ten discharges (Table 2). The lowest Reynold number in the main pipe is higher than $10^{4}$ to insure a fully turbulent behaviour (Blevins 1984, Idelcik 1969). The kinetic energy $K$ in the main pipe varies from $0.003[\mathrm{~m}]$ to $0.034[\mathrm{~m}]$.

For each discharge, pressures and discharges are recorded during $30 s$ with a sampling frequency of $100 \mathrm{~Hz}$. Then, average pressures are evaluated at 24 control sections. Head losses are found by applying Bernoulli's law (Eq.(3)) between upstream and downstream head (orifice point of view). Thus, the pressure along the main pipe is known except in the orifice box where there is no pressure sensor.

$Z_{u p .}+\frac{v_{u p .}^{2}}{2 g}+\frac{p_{u p .}}{\rho g}=Z_{d n .}+\frac{v_{d n .}^{2}}{2 g}+\frac{p_{d n .}}{\rho g}+\Delta H$

where $Z$ is the elevation in $[\mathrm{m}]$ in altitude of a given point or section, $v$ is the velocity at a given point or flowing through a given section in $[\mathrm{m} / \mathrm{s}], p$ is the pressure at a given point or section in $\left[N / \mathrm{m}^{2}\right], \rho$ the water density in $\left[\mathrm{kg} / \mathrm{m}^{3}\right]$ and $\Delta H$ is the head losses between two sections in $[\mathrm{mWC}]$.

Figure 5 shows schematically the principle of head losses evaluation for a given discharge where the origin 0 is situated at the middle orifice thickness. There are two averaging zones, either upstream or downstream, to determine local head losses produced by the tested orifice. The downstream averaging zone must be further away than the recirculation zones (taking place from 0 to $3.15 D$ downstream of the orifice (Jianhua et al. 2010)).

The determination of the head loss coefficient can be found as shown in Eq. 2. Linear head losses, which are produced by viscosity and pipe wall roughness, are assumed small enough to be neglected in the averaging zones for this study. For the higher discharge the 
Table 1. Tested orifices: (Left) Sharp-edge orifices with contraction $\beta$, thickness $\alpha$ and inner thickness $\alpha_{i}$ ratio and sharpedged angle $\theta$; (right) Elliptical orifices with dimensionless centre allipse coordinates $\left(\alpha_{x}, \beta_{y}\right)$ and axis $\left(\alpha_{a}, \beta_{b}\right)$.

\begin{tabular}{|c|c|c|c|c|c|c|c|c|c|c|c|}
\hline & \multicolumn{4}{|c|}{ Sharp-edged } & & \multicolumn{6}{|c|}{ Elliptical } \\
\hline & $\beta[-]$ & $\alpha[-]$ & $\alpha_{i}[-]$ & $\theta[\mathrm{rad}]$ & & $\beta[-]$ & $\alpha[-]$ & $\alpha_{x}[-]$ & $\beta_{y}[-]$ & $\alpha_{a}[-]$ & $\beta_{b}[-]$ \\
\hline S1 & 0.5 & 0.2 & 0.1 & 0 & & & & & & & \\
\hline S2 & 0.5 & 0.2 & 0.1 & $\pi / 12$ & E2 & 0.5 & 0.2 & 0.04 & 0.222 & 0.16 & 0.039 \\
\hline S3 & 0.5 & 0.2 & 0.1 & $\pi / 6$ & E3 & 0.5 & 0.2 & 0.04 & 0.176 & 0.16 & 0.086 \\
\hline S4 & 0.5 & 0.2 & 0.1 & $\pi / 4$ & E4 & 0.5 & 0.2 & 0.04 & 0.111 & 0.16 & 0.150 \\
\hline S5 & 0.5 & 0.2 & 0.1 & $11 \pi / 15$ & E5 & 0.5 & 0.2 & 0.045 & -0.079 & 0.155 & 0.339 \\
\hline
\end{tabular}

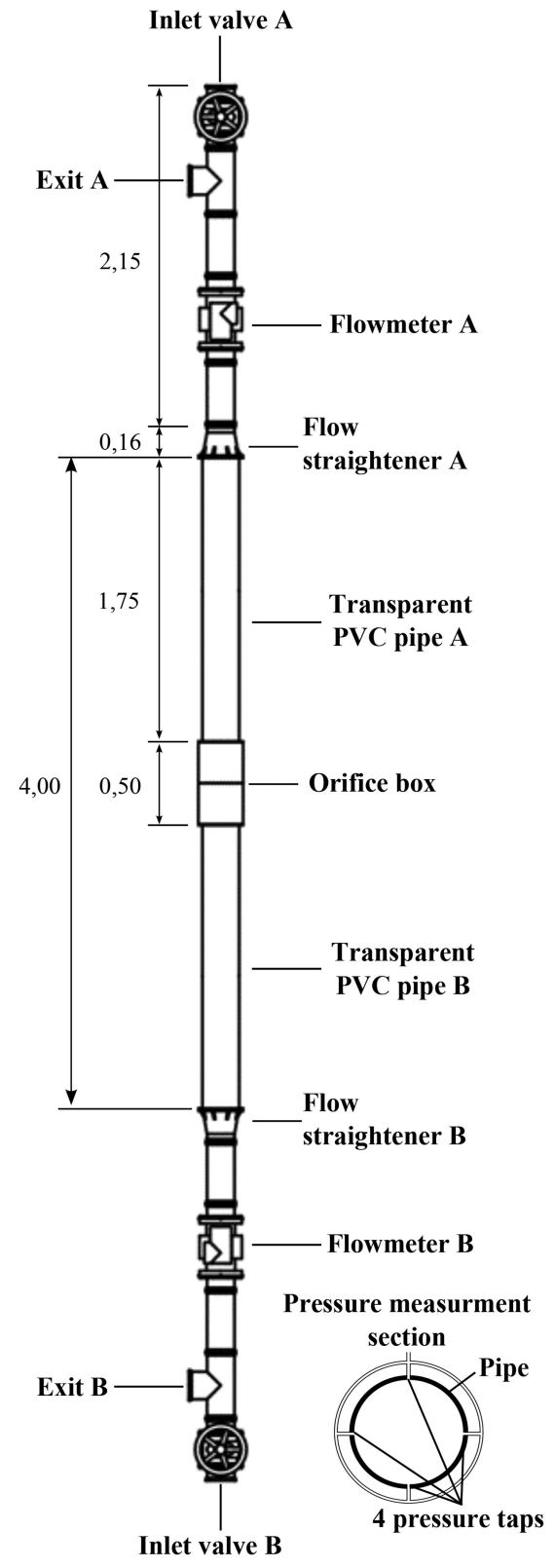

Figure 4. Experimental set-up at LCH.
Table 2. Set of discharge, kinetic energy and the Reynolds number in the main pipe.

\begin{tabular}{lll}
\hline$Q\left[\mathrm{~m}^{3} / \mathrm{s}\right]$ & $K[\mathrm{~m}]$ & $\operatorname{Re}_{P}[-]$ \\
\hline 0.0095 & 0.003 & $5.6 \cdot 10^{4}$ \\
0.0134 & 0.007 & $7.9 \cdot 10^{4}$ \\
0.0164 & 0.010 & $9.7 \cdot 10^{4}$ \\
0.0190 & 0.014 & $11.2 \cdot 10^{4}$ \\
0.0212 & 0.017 & $12.5 \cdot 10^{4}$ \\
0.0232 & 0.020 & $13.7 \cdot 10^{4}$ \\
0.0251 & 0.024 & $14.8 \cdot 10^{4}$ \\
0.0268 & 0.027 & $15.8 \cdot 10^{4}$ \\
0.0285 & 0.031 & $16.8 \cdot 10^{4}$ \\
0.0300 & 0.034 & $17.7 \cdot 10^{4}$ \\
\hline
\end{tabular}

upstream averaging zone, the linear head losses, determined using Darcy-Weisbach friction law, are equal to $0.001 \mathrm{~m}$ which are the physical limitation of the measurement for PVC pipes. Furthermore, velocity correction factors are neglected in the Bernoulli's law and the relation between head losses and kinetic energy (see Eq. 1 and 2).

$\Delta H=k \cdot \frac{v^{2}}{2 g}$

where $\Delta H$ are the head losses in $[m], \mathrm{k}$ the head loss coefficient relative to the reference section (here, equals to pipe area), $v$ the velocity in the reference section, $g$ the gravitational acceleration.

\section{RESULTS}

\subsection{Standard shape}

The first tested shape is orifice with sharp-edged angles. It is a simple way to introduce asymmetry. Figure 6 shows the average pressure along the pipe for orifice $\mathrm{S} 3$ and four discharges. Furthermore, downstream reference pressure is set to be $0[\mathrm{~Pa}]$ by convention and to compare easily results for different discharges. Figure 7 compares the difference of head losses for all sharp-edged geometry and the highest discharge. Water flow is always going from higher heads to lower heads. For filled markers (Figure 6 


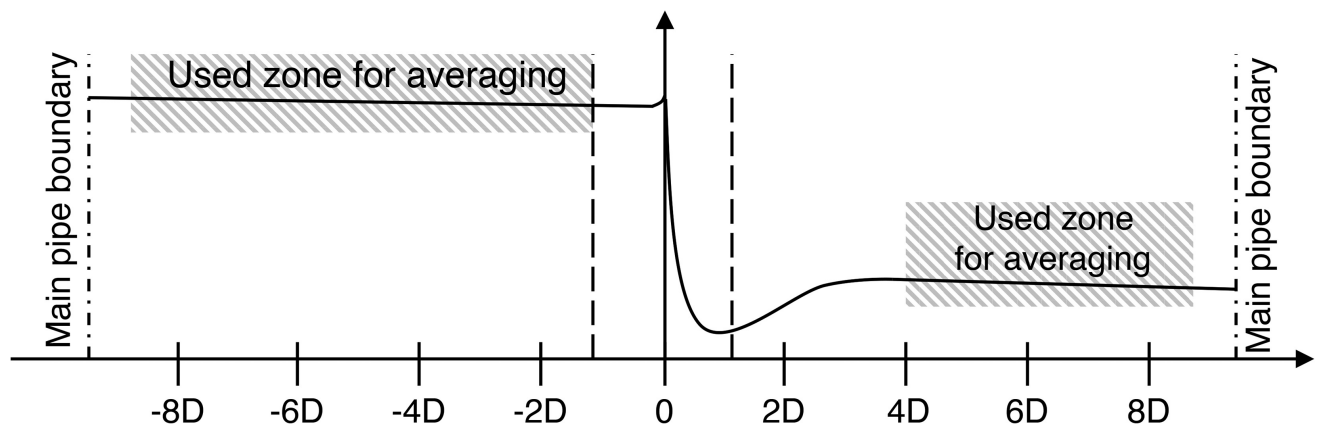

Figure 5. Principle of head losses determination (Orifice position is at 0 ).

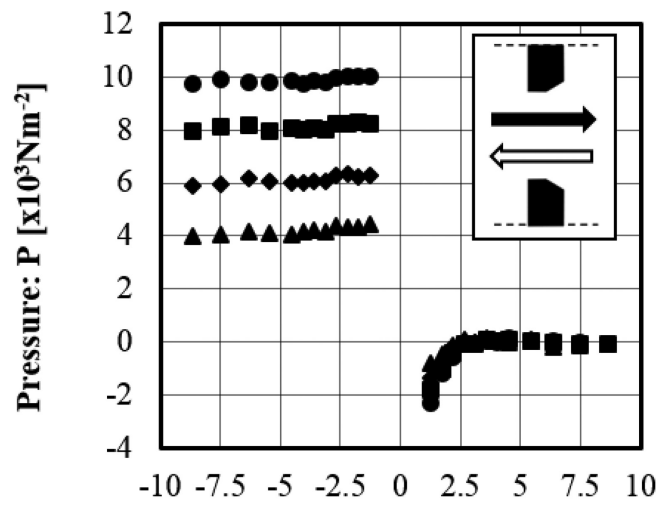

Dimensionless length: $x / \mathbf{D}[-]$

- $\mathrm{AB}-\mathrm{Q}=0.0295 \mathrm{~m}^{3} / \mathrm{s} \quad \mathrm{AB}-\mathrm{Q}=0.0267 \mathrm{~m}^{3} / \mathrm{s}$ - $\mathrm{AB}-\mathrm{Q}=0.0231 \mathrm{~m}^{3} / \mathrm{s} \quad \Delta \mathrm{AB}-\mathrm{Q}=0.019 \mathrm{~m}^{3} / \mathrm{s}$

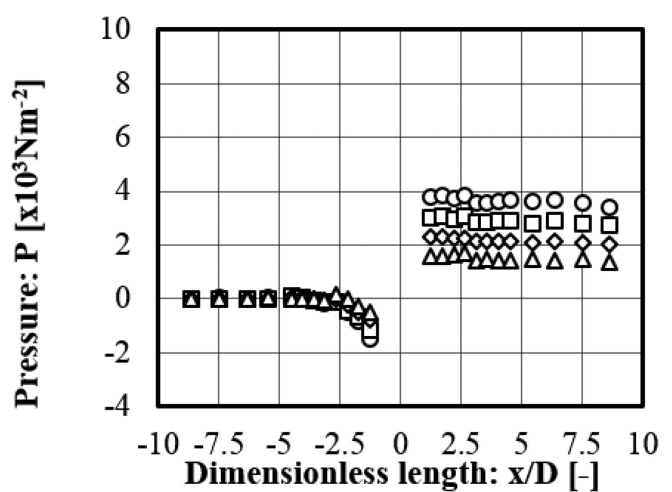

O BA - Q $=0.030 \mathrm{~m}^{3} / \mathrm{s} \quad \square \mathrm{BA}-\mathrm{Q}=0.0268 \mathrm{~m}^{3} / \mathrm{s}$ $\diamond \mathrm{BA}-\mathrm{Q}=0.0232 \mathrm{~m}^{3} / \mathrm{s} \quad \Delta \mathrm{BA}-\mathrm{Q}=0.0189 \mathrm{~m}^{3} / \mathrm{s}$

Figure 6. Pressure line for four discharges $\left(Q=0.03 \mathrm{~m}^{3} / \mathrm{s}\right.$, $Q=0.0268 \mathrm{~m}^{3} / \mathrm{s}, Q=0.0232 \mathrm{~m}^{3} / \mathrm{s}$ and $\left.Q=0.019 \mathrm{~m}^{3} / \mathrm{s}\right)$ for the sharp-edged orifices S3 (Table 1).

and 7), water flows from left to right while for empty markers is right to left. The pressure drops in the jet (in the zone $0<\frac{x}{D}<\sim 3$ for Figure 6 and in the zone $\sim-3<\frac{x}{D}<0$ for Figure 7) is counterbalanced by an

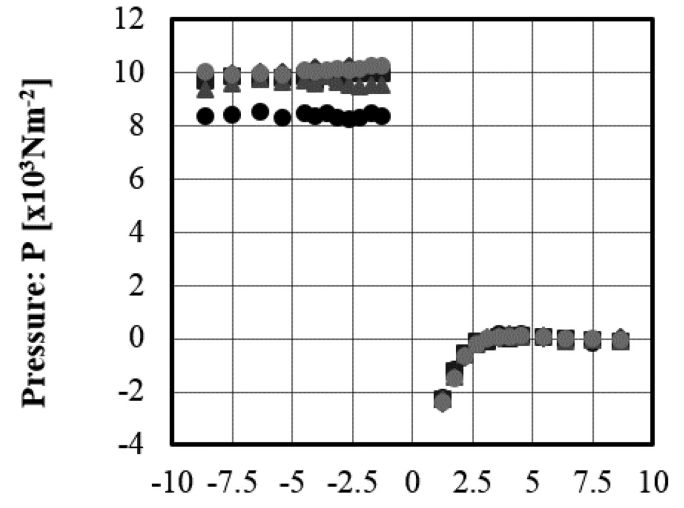

Dimensionless length: $x / D$ [-]

- $\mathrm{AB}-\mathrm{S} 1 \quad \mathrm{AB}-\mathrm{S} 2 \bullet \mathrm{AB}-\mathrm{S} 3$

$\triangle \mathrm{AB}-\mathrm{S} 4 \quad \bullet \mathrm{AB}-\mathrm{S} 5$

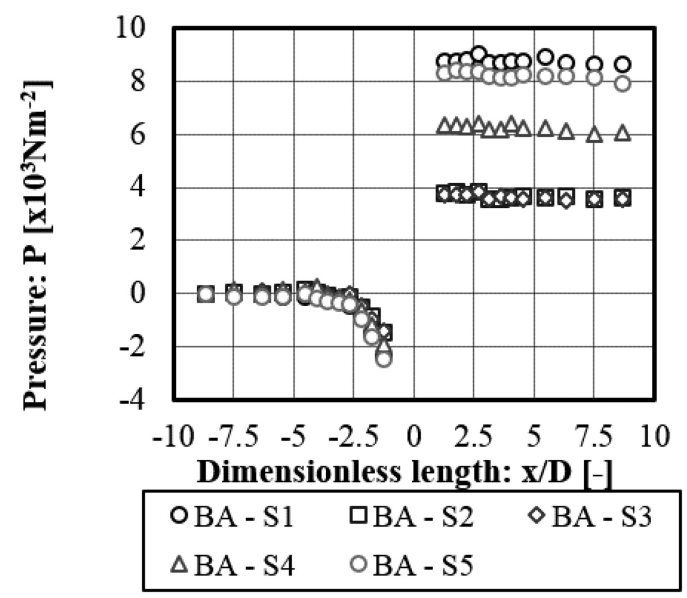

Figure 7. Pressure line for the highest discharge $\left(Q=0.03 \mathrm{~m}^{3} / \mathrm{s}\right)$ for all sharp-edged orifices (Table 1$)$.

acceleration of the flow velocity and thus the kinetic energy.

For sharp flow approach (AB flow direction as depicted in Figure 1), head losses increase slightly with the introduction of an angle, even small. However, the 
Table 3. Head losses produced by the elliptical orifices.

\begin{tabular}{llll}
\hline Orifice & $k_{A B}$ & $k_{B A}$ & $\xi$ \\
\hline S1 & 24.8 & 27.0 & 1.09 \\
S2 & 30.7 & 11.4 & 0.37 \\
S3 & 30.5 & 11.3 & 0.37 \\
S4 & 29.6 & 18.1 & 0.61 \\
S5 & 31.1 & 25.2 & 0.81 \\
E2 & 32.5 & 9.5 & 0.29 \\
E3 & 32.9 & 10.0 & 0.30 \\
E4 & 31.9 & 10.3 & 0.32 \\
E5 & 32.7 & 10.5 & 0.32 \\
\hline
\end{tabular}

head loss coefficient value is level up when the angle increases.

For the angle flow approach (BA Flow direction as depicted in Figure 1), head losses falls with introduction of small angles $\left(\theta \leq \frac{\pi}{6}\right)$ of almost $30 \%$ of the head loss value without angle (0).

All head loss coefficients for standard orifices are summarized in Table 3.

\subsection{Elliptical shape}

The second tested shape is elliptic shape. Each elliptic shape is related to a sharp-edge geometry. Head loss evaluation is performed in the same way as for sharpedged orifices (Section 4.1). All results are shown in Table 3 and depicted in Figure 8.

Results suggest that head losses in both directions are lowly impacted as there is no large difference between head loss coefficients. The elliptical shape for these orifice characteristics $(\beta=0.5$ and $\alpha=0.2)$ does not influence the head loss production in both direction. However, average head loss coefficient for elliptical shape are higher in flow direction $\mathrm{AB}$ and lower in flow direction BA.

\subsection{Discussion}

Figure 8 compares head loss coefficients evaluated for both tested geometries.

For flow direction AB, the elliptical head loss coefficients are $8 \%$ than the sharp-edged ones while BA elliptical head loss coefficients are up to more than $40 \%$ lower. Furthermore, for flow direction BA, there is no increasing of head loss coefficient for angles higher than $\frac{\pi}{6}$ unlike the standard orifice high angles.

On one hand, the increasing of head losses in flow direction $\mathrm{AB}$ can be explained by the reduction of inner orifice thickness (from $\alpha_{i}=0.1$ to $\alpha_{x}=0.04$ or 0.045 as shown in Table 1). An increasing of head losses while a decreasing of the inner orifice thickness is relevant with results found by Fratino and Pagano (2011) and Jianhua et al. (2010).

On another hand, the decreasing of head losses in flow direction BA shows that the elliptical shape induces a smaller streamline expansion as total local

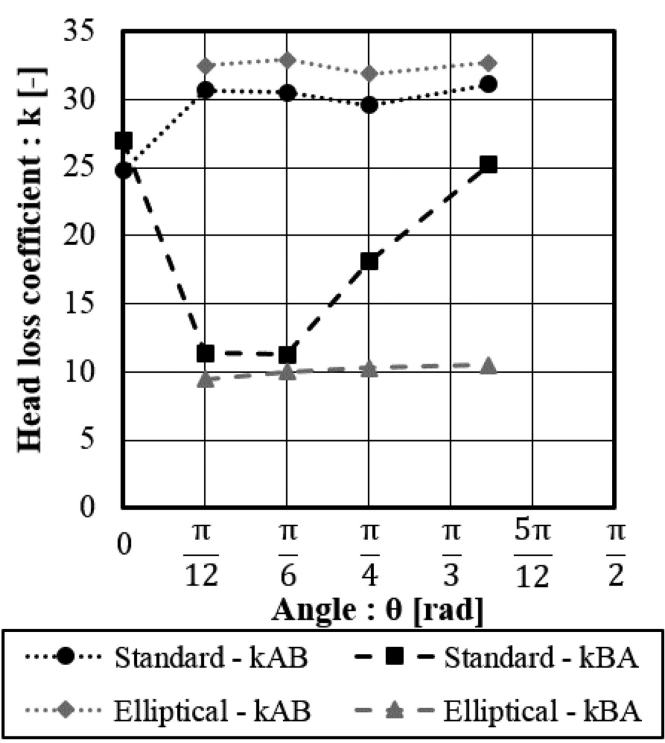

Figure 8. Head loss coefficients for sharp-edged and elliptical geometries.

head losses are smaller. In other words, the contraction downstream of the orifice seems identical for the tested elliptical shape parameters. Moreover, there is no head loss increase for elliptical orifice shapes corresponding to higher $\theta$.

\section{CONCLUSIONS}

Surge tank orifices are very helpful during a refurbishment. It allows to adapt surge tanks without huge costs and modifications. Depending on the waterway system, different orifice shapes are needed to provide target head loss coefficients in both direction: flowing in or out the surge tank. This study focuses on the orifice shapes effect on head losses and asymmetry.

Sharp-edged orifices allow to introduce a large zone of orifice asymmetries. With an increasing of the sharp-edged angle, head losses pass from symmetrical losses $(\theta=0)$ to high asymmetry $(\xi=0.37$ for $\left.\theta \in\left[\frac{\pi}{12}, \frac{\pi}{6}\right]\right)$ and lower asymmetry for angle between $\frac{\pi}{12}$ and $\frac{11 \pi}{15}$ (and certainly for higher angle).

Elliptical orifices produced slightly same head losses for both flow directions. However, elliptical shape of orifices allows to produce a higher asymmetry.

\section{ACKNOWLEDGEMENTS}

Authors want to thanks "The Ark - The foundation for innovation in Valais" and the Swiss Federal Office of Energy for the funding. 


\section{NOTATIONS}

\begin{tabular}{lll}
\hline & Unit & Description \\
\hline$a$ & $\mathrm{~m}$ & Ellipse axis \\
$b$ & $\mathrm{~m}$ & Ellipse axis \\
$d$ & $\mathrm{~m}$ & Orifice inner diameter \\
$D$ & $\mathrm{~m}$ & Pipe inner diameter \\
$k$ & - & Head loss coefficient \\
$K$ & $\mathrm{~m}$ & Kinetic energy, $\frac{v^{2}}{2 g}$ \\
$p_{i}$ & $\mathrm{Nm}^{-2}$ & Pressure at section i (Eq. 1) \\
$Q$ & $\times 10^{-3} \mathrm{~m}^{3} \mathrm{~s}^{-1}$ & Discharge \\
$R_{P}$ & - & Reynolds number \\
& & in the main pipe \\
$t$ & $\mathrm{~m}$ & Orifice thickness \\
$t_{i}$ & $\mathrm{~m}$ & Standard orifice inner \\
& & thickness \\
$v_{i}$ & $\mathrm{~m}-1$ & Flow velocity in section i \\
& & (Eq.1) \\
$x$ & $\mathrm{~m}$ & Ellipse centre coordinate \\
$y$ & $\mathrm{~m}$ & Ellipse centre coordinate \\
$Z_{i}$ & $\mathrm{~m}$ in altitude & Elevation of section i \\
& & (Eq.1) \\
$\alpha$ & - & $t / D$ \\
$\alpha_{a}$ & - & $a / D$ \\
$\alpha_{i}$ & - & $t_{i} / D$ \\
$\alpha_{x}$ & - & $x / D$ \\
$\beta$ & - & $d / D$ \\
$\beta_{b}$ & - & $b / D$ \\
$\beta_{y}$ & - & $y / D$ \\
$\Delta H$ & $\mathrm{~m}$ & Head losses prodcued \\
& & by an orifice \\
$\xi$ & - & $\frac{k_{B A}}{k_{A}}$ \\
$\theta$ & - & Sharp-edged angle \\
\hline & & \\
\hline & &
\end{tabular}

\section{REFERENCES}

Alligne, S., P. Rodic, J. Arpe, J. Mlacnik, \& C. Nicolet (2014). Determination of Surge Tank Diaphragm Head Losses by CFD Simulations. In Advances in Hydroinformatics, pp. 325-336. Springer.

Blevins, R. D. (1984). Applied fluid dynamics handbook. New York, Van Nostrand Reinhold Co. 1, 568.

Boillat, J.-L. \& P. de Souza (2004). Hydraulic System - Modélisation des systèmes hydrauliques à ecoulements transitoires en charge. Communiation LCH 16. Ecole Polytechnique Fédérale de Lausanne, Lausanne, Switzerland: Ed. Anton Schleiss.

Fratino, U. \& A. Pagano (2011). Head loss coefficient of orifice plate energy dissipator. Journal of Hydraulic Research 49(6), 830-831.

Gabl, R., B. Gems, M. Plrer, R. Klar, T. Gschnitzer, S. Achleitner, \& M. Aufleger (2014). Numerical Simulations in Hydraulic Engineering. In Computational Engineering, pp. 195-224. Springer.

Idelcik, I. (1969). Mmento des pertes de charges singulires et de pertes de charges par frottement [Handbook of singular and friction head losses]. Eyrolles, Paris.

International Standard (2003). Iso 5167-2 : Measurement of fluid flow by means of pressure differential devices inserted in circular cross-section conduits running full part 2: Orifice plates.

Jianhua, W., A. Wanzheng, \& Z. Qi (2010). Head loss coefficient of orifice plate energy dissipator. Journal of Hydraulic Research 48(4), 526-530.

Nicolet, C. (2007). Hydroacoustic modelling and numerical simulation of unsteady operation of hydroelectric systems (dissertation no. 3751). Ecole Polytechnique Fédérale de Lausanne, Lausanne, Switzerland.

Zhang, Z. \& J. Cai (1999). Compromise orifice geometry to minimize pressure drop. Journal of Hydraulic Engineering 125(11), 1150-1153. 